\title{
INDOOR AIR POLLUTION DUE TO INADEQUATE VENTILATION AND ITS IMPACT ON HEALTH AMONG CHILDREN OF LESS THAN FIVE YEARS IN EASTERN NEPAL
}

\author{
Bijay Thapa and Nitendra Chaurasia
}

\begin{abstract}
Introduction: According to WHO, half of the developing world's population depend on biomass (wood, dung and agricultural residues) and coal for such basic needs as cooking and heating. The smoke produced from the burning of these solid fuels on open fires or traditional stoves is referred to as indoor air pollution. IAP increases the risk of COPD and of acute respiratory illness in childhood, the most important cause of death among children less than 5 years of age in developing countries.

Objectives: To find out the prevalence of IAP in terms of housing, overcrowding \& ventilation. To assess the frequency, extent of biomass exposure and hazards on child health.

Materials and methods: The cross sectional study was carried out in the Urban area of Katahari V.D.C. 4,6,7,8 for the duration of 6 months from February to August 2013 among 200 households. Lottery method was used to choose the wards and households. Data were analyzed using percentages, proportions and statistical test (chi-square test).

Results: Due to excessive production of smoke and inadequate ventilation/chimney in the kitchen, such houses showed more prevalence of respiratory problems. Fifty percent of children were ill more than four times and $46 \%$ were seen at least twice. Almost all of them had experienced respiratory problems and $20 \%$ children were diagnosed with pneumonia in health facilities and treated. Ill ventilated kitchen, rooms along with dampness and absence of day light were the main factors contributing to the diseases comprising of $56 \%$.
\end{abstract}

Key words: Chulho, knowledge, ventilation, air pollution, awareness, Risk factors.

\section{Introduction}

Around 3 billion people (half of the world's population) use regularly and almost deeply rely on solid fuels (e.g. dung, wood, agricultural residues, charcoal, coal) for their basic energy needs. ${ }^{1-2}$ In most developing countries like Nepal, these fuels are burned in open fires or rudimentary stoves that give off black smoke. Children, often carried on their mother's back during cooking, are most exposed. The indoor smoke inhaled leads to pneumonia and other respiratory infections the biggest killer of children under 5 years of age. Indoor air pollution is responsible for nearly half of the more than 2 million deaths each year that are caused by acute respiratory infections. ${ }^{3}$ Immediate effects may show up after a single exposure or repeated exposures. These include irritation of the eyes, nose, and throat, headaches, dizziness, and fatigue. 
Symptoms of some diseases, including asthma, hypersensitivity pneumonitis, and humidifier fever, may also show up soon after exposure to some indoor air pollutants. Certain immediate effects are similar to those from colds or other viral diseases, so it is often difficult to determine if the symptoms are a result of exposure to indoor air pollution. Some studies suggest that fine particles have stronger respiratory effects in children than large particles. ${ }^{4}$

In analyses by the WHO, the indoor smoke from solid fuels accounted for the third highest disability-adjusted life years (DALYs) for children 0 to 4 years of age. ${ }^{5}$ Open fire cooking stoves produce heavy smoke containing Fine particles are Carbon monoxide (CO), Polycyclic aromatic hydrocarbons (PAHs), Strongly linked to pneumonia, Suggested link to low birth weight and in adults: chronic obstructive and pulmonary disease, lung cancer. ${ }^{6,7}$ Two important components are (a) the level in the home, and (b) the length of time for which each person in the home is exposed to that level. We know that typically women and young children (until they can walk), and girls (as they learn kitchen skills) are often exposed for at least 3-5 hours a day, often more. In some communities, and where it is cold, exposure will be for a much longer period each day. ${ }^{8}$

\section{Methods}

The cross sectional study was carried out in the Urban area of Katahari V.D.C. 4,6,7,8and 9 for the duration of 6 months from February to August 2013 among 200 households and "child cohort" of less than 5 years and. Lottery method was used to choose the wards. The knowledge on indoor air pollution and its risk factors, signs or symptoms and complications was assessed among householders mainly mothers, by checking ventilation's presence in all rooms as well as in kitchen along with "chulho" type used. Quantitative as well as qualitative data were collected. Data were analyzed using percentages, proportions and statistical test (chi-square test). The survey obtained informed consent from each respondent (in this case, mothers of the children included in the analysis) before asking questions. Ethical consent was taken.

\section{Results}

A total of 200 household were recruited and interviewed with mothers or the main person who cooked most of the times. Table 1 shows the types of family and the population of children in the village. In spite of the modern trend of inclining towards nuclear family in our country, this village has been following the same pattern comprising $76 \%$ of joint or extended family. Most of the household had minimum of 2 children who were under 5 years of age comprising of $62.5 \%$. extended family had upto 4 children residing at a house but were less in number contributing only $1 \%$ to it. Single child were present in $28.5 \%$ of the households.

Table 1: Family and child rearing pattern $[\mathrm{N}=200]$

\begin{tabular}{l|cc}
\multicolumn{1}{c|}{ Variables } & Frequency & Per. (\%) \\
\hline Family Type & & \\
Nuclear & 48 & 24.0 \\
Joint or extended & 152 & 76.0 \\
No. of children & & \\
1 child & 57 & 28.5 \\
2 children & 125 & 62.5 \\
3 children & 16 & 8.0 \\
4 children & 2 & 1.0
\end{tabular}

Housing standards were the main components assessed for quality life but in this study most of the houses could not meet the required standards. So, table 2 is depicting the housing standards where $73 \%$ of the houses were seen of kaccha type having nearly $20 \%$ of pukka type. Only $7.5 \%$ of the house had good cross 
ventilation and alarmingly having $56.5 \%$ and $36 \%$ of partial ventilation and ill ventilation respectively.

Table 2. Housing standards components of households [N=200]

$\begin{array}{ccc}\text { Variables } & \text { Frequency } & \mathbf{( \% )} \\ \text { House type } & & \\ \text { Kachha } & 146 & 73.0 \\ \text { Semipucca } & 15 & 07.5 \\ \text { pucca } & 39 & 19.5\end{array}$

Room ventilation

$\begin{array}{ccc}\text { well ventilated } & 15 & 7.5 \\ \text { semi ventilated } & 113 & 56.5 \\ \text { ill ventilated } & 72 & 36.0\end{array}$

Walls

$\begin{array}{ccc}\text { mud or thati } & 185 & 92.5 \\ & 15 & 7.5\end{array}$

Roof

$\begin{array}{ccc}\text { Thatched } & 146 & 73.0 \\ \text { cemented } & 15 & 7.5 \\ \text { tinned } & 39 & 19.5\end{array}$

Room No.

$\begin{array}{ccc}1-2 & 94 & 47.0 \\ 3-4 & 98 & 49.0 \\ >4 & 8 & 4.0\end{array}$

Dampness

$\begin{array}{lcc}\text { Yes } & 168 & 84.0 \\ \text { No } & 32 & 16.0\end{array}$

Kitchen

$\begin{array}{ccc}\text { ill ventilated } & 157 & 78.5 \\ \text { semi ventilated } & 23 & 11.5 \\ \text { well ventilated } & 20 & 10.0\end{array}$

Almost $93 \%$ of the houses have mud or thati walled which of course were the best places for harboring infectious agents. Accordingly, $73 \%$ of the houses were thatched or hay roofed while a bit improved tinned roof were seen in almost $20 \%$ of houses. Remaining was cemented roof of pukka house. As these villagers were living under poor socio economic condition status, most of the houses had less than 2 rooms having $47 \%$ and $49 \%$ of house had number of rooms from two to four. Only $4 \%$ of the houses had enough rooms with more than 4 rooms. Dampness was seen in more than two third of the houses. Almost $84 \%$ of the house were damp and were seen contributing to the unhealthy living conditions. Kitchen where the cooking was performed and mother working sitting children nearby were $78.5 \%$ which were ill ventilated. Smokes were seen circulating inside the kitchen and the room where children slept. Even kitchen were set outside the room on lawn, smoke still affected the room. Unfortunately only $10 \%$ of the houses had good ventilation as required.

Table 3: Relationship between frequencies of illness among children

\begin{tabular}{|c|c|c|c|c|}
\hline \multirow[t]{2}{*}{ Variables } & \multicolumn{2}{|c|}{$\begin{array}{l}\text { Frequency of } \\
\text { illness [N (\%)] }\end{array}$} & \multirow[t]{2}{*}{$\begin{array}{c}\mathbf{P} \\
\text { value }\end{array}$} & \multirow[t]{2}{*}{ OR } \\
\hline & $\begin{array}{l}<2 \\
\text { times }\end{array}$ & $\begin{array}{l}>2 \\
\text { times }\end{array}$ & & \\
\hline \multicolumn{5}{|l|}{ Kitchen type } \\
\hline Ill ventilated & $78(39)$ & $92(46)$ & 0.01 & 0.36 \\
\hline ventilated & $21(10.5)$ & $9(4.5)$ & & \\
\hline Light & & & & 1.5 \\
\hline Adequate & $9(4.5)$ & $5(2.5)$ & 0.31 & \\
\hline inadequate & $90(45)$ & $96(48)$ & & \\
\hline Damp & & & & 0.45 \\
\hline Yes & 78(39) & $90(45)$ & 0.04 & \\
\hline No & $21(10.5)$ & $11(5.5)$ & & \\
\hline $\begin{array}{l}\text { Room } \\
\text { ventilation } \\
\text { Well vent }\end{array}$ & $10(5)$ & $5(2.5)$ & & \\
\hline Ill vent & $40(20)$ & $73(36.5)$ & 0.00 & - \\
\hline Semi vent & $49(24.5)$ & $23(11.5)$ & & \\
\hline
\end{tabular}

Table 3 shows the relationship in between frequency of illness and the different variables. Ill ventilated kitchen type, absence of light in room, dampness presence and mostly ill ventilated kitchen had significant role in contributing respiratory illness more than twice in 6 months. Most significant relation in between absence of room ventilation was seen in this study comprising 
$36.5 \%$ to have illness more than twice and $20 \%$ less than twice. Absence of lighting inside the room comprised $48 \%$ where as almost equal percentage of $45 \%$ is seen for less than twice frequency of illness. Forty five percent of the children are affected more than twice and $39 \%$ are less than 2 times.

\section{Discussion}

Due to excessive production of smoke and inadequate ventilation/chimney in the kitchen, such houses showed more prevalence of respiratory problems. Practice of carrying children alongside while cooking was more seen in developing countries. Due to this reason the adverse effect of smoke was seen both in mother and children. Despite the knowledge about smokeless/improved chulo and its benefits, use of such chulos was found to be minimum, the main reasons being poverty, easily accessible firewood and coal, lack of proper trainees for construction of smokeless chulo.

Results of this study also coincide with a meta-analysis of 24 studies by Dherani et al. produced a summary estimate of $1.78(95 \%$ CI: $1.45,2.18$ ) for the relationship between household use of solid fuels (wood, dung, charcoal, and coal), relative to use of fuels considered "clean" (electricity, gas, or kerosene), and ALRI in children $<5$ years of age ? $^{\circ}$

In this study the association between absence of adequate lighting standard and the frequency of illness is significant. It means the frequency of respiratory illness in children was directly related with the bright rooms with adequate lights. As found in more recent studies, ALRI risks of a similar magnitude associated with solid fuel use, our study also have concluded with the same results. ${ }^{10-11}$

To our knowledge, most of the study have concluded that the solid fuel use was the main factor for respiratory illness which is also proven in a study done in the Dhading district,
Nepal attributed approximately $50 \%$ of ALRI in children $<5$ years of age to household use of solid fuel-burning stoves. ${ }^{12}$ This results coincides almost with our study as the scenario of our country coincides comprising of $56 \%$. It may be the fact that solid fuels basically "cow dung" are mostly used in terai region. In this study use of kerosene and LPG were less commonly found because of the socio- economic status of the population. As the study period was from February month during the cold season so, the exposure could have been for a long time.

Our analysis also evaluated a range of socioeconomic factors like including parental occupation and education, land ownership, house size and construction materials, and house ownership which is not shown in this article. As we have in this study mostly focused on the child's health, father's occupation has no strong relationship nevertheless we shall not deny that absolutely. In a study done in Zimbawe about two-thirds $(66 \%)$ of children lived in households using biomass fuels and 16\% suffered from ARI during the 2 weeks preceding the survey interview $^{13}$ where our study also shows near about results which added the strength to our study. Information on ARI is based on mothers' reports and no clinical measurements were undertaken, and smoke exposure was ascertained from type of fuel used for cooking. Although the symptomatic definition used here is intended to measure acute lower respiratory infections (ALRI) in children, some acute upper respiratory illness may have been included in the reported prevalence. Because it is not possible to separate ALRI from these data, we use the term ARI in this study, not ALRI. In developing countries such as Nepal, where clinical data on ARI are usually not available or very weak, the symptomatic definition of illness used here has been shown to provide a fairly accurate assessment of ARI in the population. ${ }^{14}$ Moreover, indoor air pollution 
measurements in several developing countries have shown fuel type to be the best single indirect indicator of household pollution levels. ${ }^{15}$ Despite these problems in the measurement of smoke exposure and ARI, the consistency in the size of crude and adjusted effects of biomass fuel use on childhood ARI suggests a possible 'exposure-response' relationship. To validate this relationship, our research needs to be followed by carefully designed epidemiological studies, with direct measures of smoke exposure and clinical measures of ARI. Such research is important because a large proportion of households in Nepal and other developing countries rely on biomass fuels for household energy and ARI are a leading cause of ill health and death in young children.

\section{References}

1. Bonjour S, Adair-Rohani $\mathbf{H}$, Wolf $\mathbf{J}$, Bruce $\mathbf{N}$, Mehta S, Pruss-Ustan A, et al. In press. Solid fuel use for household cooking: country and regional estimates for 1980-2010. Environ HealthPerspect

2. Bruce N, Perez-Padilla R, Albalak R. 2000. Indoor air pollution in developing countries: a major environmental and public health challenge. Bull WHO 78(9):1078-1092.

3. Gordon B et al. Inheriting the world, the Atlas on Children's Health and the Environment. Geneva, World Health Organization, 2004

4. World Health Organization. Air Quality Guidelines. Geneva, World Health Organization: Department of Protection of the Human Environment, 2005.

5. World Health Report 2002 (www.who.int/whr/2002/en/).

6. Environmental threats to children. In: Children in the New Millennium, Environmental Impact on Health. UNEP, UNICEF \& WHO, 2002

7. Smith KR et al. Chapter 18: Indoor smoke from household use of solid fuels. In: Ezzati
Eds.Comparative quantification of health risks: The global burden of disease due to selected risk factors, Vol 2. Geneva: World Health Organization, 2004

8. Addressing the links between indoor air pollution, household energy and human health. Based on the WHO-USAID Consultation on the Health Impact of Household Energy in Developing Countries (Meeting report).Geneva, World Health Organization, 2002.

9. Dherani M, Pope D, Mascarenhas M, Smith KR, Weber M, Bruce N. 2008. Indoor air pollution from unprocessed solid fuel use and pneumonia risk in children aged under five years: a systematic review and meta-analysis. Bull WHO 86(5):390-398.

10. Bautista LE, Correa A, Baumgartner J, Breysse P, Matanoski GM. 2009. Indoor charcoal smoke and acute respiratory infections in young children in the Dominican Republic. Am J Epidemiol 169(5):572-580.

11. Rehfuess EA, Tzala L, Best N, Briggs DJ, Joffe M. 2009. Solid fuel use and cooking practices as a major risk factor for ALRI mortality among African children. J Epidemiol Community Health 63(11):887-892.

12. Dhimal M, Dhakal P, Shrestha N, Baral K, Maskey M. 2010. Environmental burden of acute respiratory infection and pneumonia due to indoor smoke in Dhading. J Nepal Health Res Counc $8(1): 1-4$.

13. Mishra V. Indoor air pollution from biomass combustion and acute respiratory illness in preschool age children in Zimbabwe International Journal of Epidemiology 2003;32:847-853

14. Cabaraban, MC. Rural Mother's Management of Acute Respiratory Infection (ARI) in Region 10: Project Report to the Health Research Network. Cagayan de Oro, Philippines: Research Institute for Mindanao Culture, Xavier University. 1993.

15. Mehta S, Smith KR, Balakrishnan K et al. Using household characteristics to predict respirable particulate levels in rural households in Andhra Pradesh, India. Paper presented at the 9th International Conference on Indoor Air Quality and Climate, Monterey, California. June 30-July 5 2002.

Address of correspondence: Dr. Bijay Thapa, Lecturer, Department of Community Medicine, Nobel Medical College and Teaching Hospital, Biratnagar, Nepal. Email:tbijay@hotmail.com 